\title{
ARTE E POLÍTICA NO ROMANCE BOLOR, DE AUGUSTO ABELAIRA
}

\author{
Isabelita Maria Crosariol ${ }^{1}$
}

RESUMO: O artigo parte do pressuposto de que pensar as relações entre arte e política no romance Bolor, de Augusto Abelaira, não significa simplesmente verificar os termos presentes na obra que fazem referência à política, mas sobretudo questionar até que ponto a forma adotada pelo romance (a de um diário escrito a várias mãos) também é política, na medida em que permite ao leitor perceber a superfície textual como uma forma de partilha do sensível, ou seja, como um espaço democrático que evidencia quem são os cidadãos - aqueles que tomam parte na vida política - por meio de recortes do comum.

PALAVRAS-CHAVE: arte, política, Augusto Abelaira.

ABSTRACT: This essay assumes that thinking the relations between art and politics in the novel Bolor, by Augusto Abelaira, doesn't mean simply verify the terms in this literary work which refer to politics, but mainly to put in question until what point the form adopted (of a diary written by several hands) is also political, since it permits to the reader to realize the textual surface as a way of distribution of the sensible, in other words, as a democratic space which makes evident the ones who take part in the political life - the citizens - by means of the delimitations of the common.

KEY-WORDS: art, politcs, Augusto Abelaira.

Se a arte é política, ela o é enquanto os espaços e os tempos que ela recorta e as formas de ocupação desses tempos e espaços que ela determina interferem com o recorte dos espaços e dos tempos, dos sujeitos e dos objetos, do privado e do público, das competências e das incompetências, que define uma comunidade política.

Jacques Rancière

Um diário sem política é um diário falso, pelo menos se for escrito por ti.

Augusto Abelaira

Bolor, romance do escritor português Augusto Abelaira, corresponde a uma das mais importantes obras da Literatura Contemporânea de seu país. Publicado em 1968, em plena vigência do regime salazarista, o romance se apresenta como um diário escrito

\footnotetext{
${ }^{1}$ Doutoranda em Estudos da Literatura pela PUC-Rio
} 
a várias mãos, em que a autoria e a ordem dos registros são freqüentemente questionadas, assim como a própria (in) utilidade da escrita. Contudo, na obra, mais importante do que verificar quem fala (ou quem escreve), ou tentar estabelecer o que foi escrito antes ou depois, é verificar de que maneira a forma adotada implica a caracterização da superfície textual como uma forma de partilha do sensível, ou seja, como um "sistema de evidências sensíveis que revela, ao mesmo tempo, a existência de um comum e dos recortes que nele definem lugares e partes respectivas" (RANCIÈRE, 2005a, p. 15, grifo do autor).

Em sua conferência intitulada "Política da Arte", Jacques Rancière, ao citar exemplos de manifestações contemporâneas da política da arte (que definem uma relação entre arte, trabalho e espaço social), comenta a respeito do projeto "Eu e nós", criado pelo grupo de artistas franceses "Acampamento Urbano". O projeto consistia na criação de uma nova forma de espaço público acessível a todos, que deveria ficar sob a guarda de todos, mas que só poderia ser ocupado por uma pessoa de cada vez, de forma a permitir "o recolhimento de um Eu possível no Nós" (2005b, p.1). Trata-se de uma proposta bastante semelhante à desenvolvida no romance de Abelaira, na medida em que em Bolor cada eu, um de cada vez, recolhe-se em seu diário na tentativa de (re) criar e descobrir a si mesmo, ao mesmo tempo em que descobre um ele, e conseqüentemente um nós. Tanto o projeto do grupo de artistas, quanto o romance de Abelaira, funcionam como espaços democráticos, como lugares aonde todos não apenas têm acesso, como também em que todos tomam parte e se tornam cidadãos. Em ambos os casos, evidencia-se a arte como uma forma de partilha que, ao mesmo tempo em que possibilita o recolhimento do eu, é um espaço do ele e do nós, um espaço comum em que cada um de seus recortes significa.

Não por acaso, no capítulo do romance intitulado "15 de fevereiro" - ou ainda, se se preferir, na entrada do diário-Bolor que recebe essa data -, Humberto, marido de Maria dos Remédios, comenta que o objetivo de seu diário é o de observar minuciosamente as suas relações com os outros (amigos e conhecidos), verificar se seus diálogos gozam da propriedade comutativa, se são intermutáveis, "se onde está $e u$ poderia estar indiferentemente ele". (ABELAIRA, 1978, p. 51). Nesse ponto, ainda seria possível acrescentar que o objetivo do diário também é verificar se onde está $e u$ poderia estar nós, já que muito mais do que se referir a um eu, o romance-diário, ao 
abordar as relações com os outros a partir do relato de vários eus, permite perceber a existência de um "eu no nós", a existência de recortes no comum.

Assim sendo, se é o "recorte dos tempos e dos espaços, do visível e do invisível, da palavra e do ruído que define ao mesmo tempo o lugar e o que está no jogo na política como forma de experiência" (RANCIÈRE, 2005a, p.16), dissociar o romance Bolor do aspecto político é um grande equívoco. Tão equivocado quanto desconsiderar o teor político da obra, é pensar que ela está presente apenas nas referências ao fascismo, a uma guerra, à vinda do Papa, ao Estado Novo, quando, na verdade:

[...] a arte não é política antes de tudo pelas mensagens que ela transmite nem pela maneira como representa as estruturas sociais, os conflitos políticos ou as identidades sociais, étnicas ou sexuais. Ela é política antes de mais nada pela maneira como configura um sensorium espaço-temporal que determina maneiras de estar junto ou separado, fora ou dentro, face a ou no meio de... Ela é política enquanto recorta um determinado espaço ou um determinado tempo, enquanto os objetos com os quais ela povoa este espaço ou o ritmo que ela confere a esse tempo determinam uma forma de experiência específica, em conformidade ou em ruptura com outras. (RANCIÈRE, 2005b, p. 2)

Segundo Rancière, assim como a política, a arte constrói ficções, rearranjando as relações entre o que se vê e o que se diz, entre o que se faz ou se pode fazer, embaralhando a repartição entre a língua dos assuntos públicos e a dos assuntos domésticos. Porém, a arte não produz essas ficções para a ação política, mas no seio de sua própria política, ocupando as formas de recorte do espaço do sensível comum, e redistribuindo as relações entre ativo e passivo, singular e comum, aparência e realidade. A arte faz política ao produzir "formas de reconfiguração da experiência que são o terreno sobre o qual podem se elaborar formas de subjetivização políticas que, por sua vez, reconfiguram a experiência comum e suscitam novos discursos artísticos" (RANCIÈRE, 2005b, p. 10). Dessa forma, o teor político de Bolor não se restringe meramente ao emprego de termos que fazem referência à política. Mais importante do que esses termos é a maneira como a obra faz política por meio do recorte sensível da comunidade, é a maneira como ela recorta um espaço específico de ocupações comuns, para determinar quais são os objetos que delas fazem parte (ou não), e quem são os sujeitos que participam (ou não) dessas ocupações. 
Eis a razão pela qual Bolor é uma narrativa repleta de recortes, recortes esses presentes não apenas na escolha dos dias que se deseja registrar, mas também na escolha do espaço (não apenas físico, mas também social) sobre o qual se escreve. Também a escrita cumpre na obra essa função de recorte, pois recorta a experiência ao registrar apenas o momento que se deseja congelar. O romance-diário, por sua vez, devido a esses inúmeros recortes que o compõem, acaba por se assemelhar a um mosaico, no qual as experiências relatadas por seus vários autores unem-se para formar um todo sensível comum.

A opção por um diário escrito por várias pessoas assume fundamental importância nesse contexto. Contudo, partindo da idéia de que uma escrita coletiva não caracteriza o gênero autobiográfico diário, convém pensar como a forma de um diário, enquanto espaço de recolhimento exclusivo de um $\mathrm{eu}$, poderia contribuir, no romance, com a partilha do sensível. Além disso, convém pensar ainda como a apropriação da forma de um diário (como algo íntimo, pessoal, privado) propiciaria um ganho para o estabelecimento de relações entre arte e política. Para tanto, faz-se necessário em primeiro lugar refletir até que ponto um diário poderia ser concebido como um lugar exclusivo do eu, até que ponto o diário não é o lugar do outro, ou ainda, até que ponto um eu, ao falar de si em um diário, ao se reconstruir por meio da escrita, não cria um outro eu, percebendo assim que "Eu é um outro", como afirmou o poeta Rimbaud.

A respeito da presença do outro no diário, Béatrice Didier comenta que, embora pareça o lugar privilegiado do segredo e do refúgio do indivíduo, o diário é, na verdade, "um gênero muito aberto à presença do outro. $\mathrm{O}$ outro é em primeiro lugar o assunto de muitas páginas. Pois, se o diarista tem tendências a tecer análises de si mesmo, esta análise torna-se muito rapidamente a de suas relações com o outro". (DIDIER apud MACIEL, 2002, p. 61). Dessa forma, não há como escrever um diário sem que a figura do outro não esteja presente, não há como escrever sobre si sem que se escreva sobre um outro, ainda que esse outro seja um eu recriado. Nesse processo, tanto esse eu, quanto o outro, serão sempre seres fragmentários, na medida em que se organizam a partir do relato daquele que escreve. Logo, escrever sobre si é (re) construir-se, falar a si mesmo e, ao mesmo tempo, colocar-se na pele do outro para descobrir a si próprio. É em razão disso que, em “28 de março”, Maria dos Remédios escreve: 
Agora, porém, desejaria conjugar-me na minha primeira pessoa e não na tua, desejo recuperar-me, ser eu, independentemente daquilo que és - e a caneta emperra, já não sei o que escrever. Desejo dirigir-me a mim mesma, fazer de mim a segunda pessoa: "Tu, Maria dos Remédios..., que és assim e assado", mas não sei. A segunda pessoa que sempre me ocorre é a tua: "Sabes, Humberto, que eu sou assim e assado?" E pelo próprio facto de me dirigir a ti, já não sou bem eu.

De súbito, à falta de saber o que faça, sinto outra vez vontade de me trocar por ti, de procurar na tua primeira pessoa o segredo verdadeiro. De escrever, em busca não sei de quê. [...]

Concluo, então: é mais fácil escrever em teu nome, falar por ti - e para mim, como se efetivamente te dirigisses a essa mulher que sou eu. (ABELAIRA, 1978, p.104-5).

No trecho acima exposto, observa-se claramente a impossibilidade de Maria dos Remédios de ser no diário um eu sem que, ao mesmo tempo, deixe de ser outro, pois o desejo de ser eu revela-se como um impedimento para a escrita, na medida em que o eu que escreve assume para si uma máscara ao tentar se conjugar em sua primeira pessoa. Por esse motivo, em "1 de abril", lê-se o seguinte registro de Humberto (ou talvez de Aleixo; quem sabe ainda de Maria dos Remédios):

Como os primitivos que nos grandes ritos anuais, às duas por três acabam por acreditar no poder da máscara... Sinto-me outro, com outros poderes, já não sou eu... ou sou verdadeiramente eu. Afasto assim a vida quotidiana, abro um parêntesis na rotina diária e familiar e esse parêntesis tem, como entre os primitivos que se mascaram, qualquer coisa de secreto. De misterioso. E represento um papel bem mais rico do que o meu, bem mais dramático. (ABELAIRA, 1978, p. 113)

Eis então o poder da máscara criada durante a escrita do diário... Máscara que transforma o eu do diário em um eu (re) inventado, cujo discurso deve ser sempre questionado, não apenas porque quem escreve representa um papel, mas também pelo fato de o diário ser um gênero elaborado a partir da memória. Dessa forma, enquanto o diário possibilita a criação de um espaço em que o eu se confunde com o outro (ao mesmo tempo em que é um outro), o romance Bolor, ao se apropriar do formato diarístico, possibilita a percepção de que onde está $e u$, poderia estar ele, ou até mesmo nós. Ao fazer isso, o romance evidencia, em primeiro lugar, uma forma de partilha que define quem toma parte no comum e, em segundo lugar, uma forma de partilha que determina quem toma parte no fato de governar e de ser governado, que define quem é o $e u$, o ele, e o nós - pronome que, embora seja elástico, corresponde a uma eterna 
equação: "Nós $=$ X. Substituindo: Nós $-\mathrm{Eu}=\mathrm{X}$. Quem era X? Tu? O Humberto? Um sonho?" (ABELAIRA, 1978, P. 148).

$\mathrm{O}$ romance inicialmente parece recorrer à forma de um diário íntimo com o intuito de evidenciar o âmbito privado, a vida íntima, os diálogos e os encontros que ocorrem entre um grupo de indivíduos, e que se ocultam sob a proteção de quatro paredes. Contudo, um olhar atento principalmente às subversões feitas ao formato diarístico, permite perceber um outro aspecto envolvendo a forma do romance, pois, ao contrário do que ocorre em um diário íntimo, o diário-Bolor não é um diário que fica escondido, guardado, longe do alcance dos olhos dos outros, para que ninguém o leia. Bolor é um diário compartilhado, em que os outros (e nesse termo "outros" também se inclui o leitor) atuam como leitores e como co-autores, conferindo a essa res privata, uma dimensão pública.

De acordo com Lafer (2004, p. 1), a idéia de que "público é não só aquilo que é comum a todos, por afetar a todos - mas igualmente o que é acessível ao conhecimento de todos em contraposição ao privado, encarado como aquilo que é reservado e pessoal, no plano político é uma idéia ligada à democracia". Nesse sentido, se na elaboração do romance Bolor, o que era uma forma privada (o diário íntimo) torna-se uma forma pública - permitindo, assim, a quaisquer dos leitores, "ver como, onde e por que tais e quais decisões foram tomadas em função do interesse de todos” (LAFER, 2004, p. 1) é porque o romance pode ser concebido como um espaço democrático, que surge em oposição ao contexto ditatorial, e que, ao colocar o indivíduo em condição de saber, torna-o cidadão.

É em razão disso que a superfície textual, ao partir da forma de um diário para se constituir como romance, corresponde a uma forma de partilha do sensível, na medida em que "a partilha democrática do sensível faz do trabalhador um ser duplo. Ela tira o artesão do "seu" lugar, o espaço doméstico do trabalho, e lhe dá o "tempo" de estar no espaço das discussões públicas e na identidade do cidadão deliberante." (RANCIÈRE, 2005a, p. 65).

Assim sendo, se em Bolor as experiências registradas por cada personagem podem ser isoladamente concebidas como testemunhos subjetivos, como elementos de um espaço privado que dizem respeito a um espaço doméstico, tomadas uma em relação com as outras, em uma visão de conjunto, elas adquirem o caráter de experiência social, 
de algo inerente a um nós. O romance-diário torna-se então espaço compartilhado desse nós composto pelos vários eus que lêem o diário e que também o escrevem, e assim alcança a esfera pública em um processo no qual a folha em branco, esse tudo-nada pardacento, ao ser "pintada" por seus vários autores, "intervém ao mesmo tempo como princípio de revolução "formal” de uma arte e princípio de re-partição política da experiência comum”. (RANCIÈRE, 2005a, p. 23-4).

Isso significa que Bolor, ao mesmo tempo em que inova do ponto de vista político (ao apresentar uma forma que também é política), também inova do ponto de vista estético, uma vez que, nesse romance de Abelaira, os dois pontos de vista fundemse. Logo, no plano estético-político, a forma híbrida de um romance-diário funciona como meio de trazer um caráter de novidade sempre necessário ao gênero romanesco que, ao criar uma interface entre o livro (como suporte para o romance) e o diário (que tinha o caderno como suporte), muda a aparência trivial de um romance, para que aquilo que se escreve deixe de ser parecido com esquemas pré-fabricados. Com isso, o que se propõe é uma nova forma de construir o mundo e o homem, já que ambos, no romance, são descritos como elementos que podem ser reescritos e recriados, não como elementos que possuem uma forma plena, fechada, acabada.

Escrever segundo uma nova forma é, portanto, um modo de descobrir a realidade, de perceber a situação real do mundo atual, de se entrar em contato com o novo. Em função disso, no romance de Abelaira, a criação de uma interface nova por meio do entrelaçamento de gêneros (diário e romance) e de suportes (livro e caderno), é o que cria a possibilidade da descoberta e da invenção, a possibilidade da existência de uma vida nova, já que:

É, antes, na interface criada entre "suportes" diferentes [...] que se forma essa "novidade" que vai ligar o artista, que abole a figuração, ao revolucionário, inventor da vida nova. Essa interface é política porque revoga a dupla política inerente à lógica representativa. (RANCIÈRE, 2005a, p. 23)

Mesclando gêneros e suportes, aproveitando o layout de um diário na estrutura romanesca, a estrutura adotada pelo romance-diário promove, portanto, a mescla igualitária de imagens e de signos, insere a arte no cenário de cada vida em particular, ao mesmo tempo em que cria uma nova interface, uma interface política. Em Bolor, a reflexão sobre o processo de escrita não está presente, portanto, apenas nos comentários 
das personagens sobre a (in) utilidade do ato de escrever um diário; também está presente na discussão sobre o entrelaçamento de suportes e de gêneros, e de sua relação com a política, conforme se percebe na discussão travada entre Humberto e Aleixo, registrada em "25 de fevereiro":

- De que falávamos nós quando nos encontramos? - disse ele também.

- Sobretudo de política, respondi.

- Precisamente. Aliás só dei por isso ao escrever o diário... Estamos quase todos os dias um com o outro e pelo menos metade das nossas conversas são dedicadas à política, metade dos pensamentos também.

- O teu diário é um diário político.

- De maneira nenhuma! É um diário íntimo, mas grande parte do que nele escrevo é sobre política. Os boatos, por exemplo. Não sucede o mesmo contigo? - Recomeçara a brincar com o anel, mas nem sempre era feliz, muitas vezes tinha de o agarrar já perto da borda da mesa, quase a cair. - Não falas de política no teu diário? [...]

Pego-lhe no caderno, aperto-o nas mãos, avalio-lhe o peso, interrogome sobre o mistério de cento e trinta gramas de papel e de tinta poderem conter uma parte da minha própria vida (e não apenas a dele). Continuo:

- Escrevo há dois meses... Não, não falo de política, e só agora dou por isso.

O anel escapara-lhe dos dedos, parecia uma bala, o Aleixo acocoravase nesse instante (mas seria rigorosamente nesse instante, a memória não trairá?) debaixo da mesa. Quando regressou, disse:

- Escreves um romance...

- Que disparate!

- Qualquer coisa que possas publicar... Não sonharás com a glória? continuava a rir-se, o anel enfiado no dedo. - Um diário sem política é um diário falso, pelo menos se for escrito por ti. (ABELAIRA, 1978, p. 80-2, grifo do autor)

O diário que Humberto escreve é um romance para ser publicado, ou um diário político - já que um diário sem política seria falso se fosse escrito por ele? O diário que Aleixo escreve, por sua vez, é um diário íntimo no qual ele escreve sobre política, ou apenas um diário político, na medida em que pelo menos metade de suas conversas com Humberto são dedicadas à política, metade dos seus pensamentos também? Mas, em que medida um diário íntimo, ou mesmo um romance, deixam de ter um vínculo com a política se, em última análise, a vida depende dela, se a política entra dentro das casas mesmo sem se querer?

A relação entre vida, política, e arte, essa parece ser a verdadeira questão evidenciada no diálogo entre os dois amigos. Assim sendo, questionar a forma de uma escrita vinculada à política é sobretudo uma forma de questionar a própria estrutura 
política vigente, que faz com que o indivíduo sinta que o mundo se faz sem ele, sem o seu voto, nem sequer contra o seu voto, "cortado da vida social, se por vida social entendermos a construção de uma sociedade nova" (ABELAIRA, 1978, p. 83), é uma forma de mostrar que a política está em tudo, mesmo quando não parece estar, que mesmo sua negação já é uma atitude política.

Nesse ponto, chega a ser surpreendente a audácia da publicação do romance em plena ditadura portuguesa (momento de intensa repressão e de silenciamento), já que Bolor não apenas insinua as implicações de uma identidade revelada em um contexto de repressão - ao confundir as identidades de quem escreve o diário -, como também expõe o mal-estar de um indivíduo que, em um contexto de censura, sente sua vida vazia, não se sente um político, e por isso afirma:

- Há em mim uma certa energia política, digamos assim. Sinto necessidade, através do voto, através de um ou outro artigo escrito para o jornal, sei lá do que mais!, de dar a minha contribuição à marcha do mundo, isto é, sinto necessidade de pesar, por pouco que seja, nos actos governativos, nas grandes decisões... E que sucede? Não voto, não posso escrever esses artigos... Se eu fosse verdadeiramente um político ou um revolucionário a sério ainda poderia tentar essa influência por outra maneira. Mas não. Efectivamente não sou um político, percebes? (ABELAIRA, 1978, p. $82)$.

O relato das experiências de um indivíduo e o estabelecimento de suas relações com a política são extremamente comprometedores nesse contexto, ainda mais levandose em conta que essas experiências estão documentadas no diário-Bolor. Dessa forma, se o diário íntimo é um gênero comprometido em respeitar o calendário, o romance também apresenta datas, porém, a veracidade do conteúdo registrado é colocada em xeque, uma vez que a disposição dos registros não segue a ordem cronológica. Escrever em voz baixa, confundindo as datas, bem como a autoria dos registros, torna-se, portanto, uma alternativa para expor o que não se ousa dizer em voz alta, ao mesmo tempo em que constitui uma forma de criar uma experiência. Logo, se Humberto é um advogado que se caracteriza pela inação, se Maria dos Remédios é uma cantora lírica frustrada, e se Aleixo é um artista plástico que acaba por render-se à publicidade, escrever um diário torna-se para eles uma forma de fazer algo, de compensar aquilo que poderia ser feito no mundo real, e de não se sentirem nulos. 
De acordo com Blanchot, parece haver no diário a compensação de uma dupla nulidade, pois aquele que nada faz de sua vida escreve que não faz nada, e assim, tem algo de feito; já aquele "que se deixa desviar da escrita pelas futilidades do dia, agarrase a esses nadas para contá-los, denunciá-los ou gozá-los, e eis um dia preenchido" (BLANCHOT, 2005, p. 274). Escrever no diário corresponde então a uma maneira de escapar ao silêncio, de se proteger do esquecimento e do desespero de não ter nada a dizer, a um modo de encontrar refúgio e de descobrir que existe um dentro:

Surpreendo o Aleixo a escrever num caderno muito parecido com este (ou deixar-se-ia surpreender de propósito?).

- Um diário íntimo... - digo, vagamente recordado de que já uma vez lhe ouvi uma frase semelhante (vagamente desejoso, agora, ao cobrir o papel com palavras azuis, de fugir, ao menos, eu, a escrever um diário íntimo, de transformar este caderno num meio de libertar de mim mesmo, de falar interessadamente dos outros).

- Porque não?

- Ah, tens vida íntima - acrescento. - Supus que não tivesses, só tivesses fora.

- O Aleixo riu-se - tirara o anel do dedo e fizera dele um pião, obrigando-o a rodopiar sobre o tampo da mesa.

- Descobri que tinha dentro, precisamente ao escrever este diário. Se quiseres: sempre suspeitei que não tinha somente fora... mas dentro... bom, não tinha certeza. - Parando com uma pancada seca sobre a mesa, a rodopiar o anel: - Também escreves um diário, não escreves? Se escrevo! Mas não lhe respondo. (ABELAIRA, 1978, p. 78-9)

Escrever um diário como meio de se libertar de si mesmo, como meio de falar desinteressadamente dos outros. Escrever um diário como forma de se colocar na proteção dos dias comuns, como meio de se descobrir... A escrita como remédio, mas também como veneno, como forma de se proteger da morte (já que quem escreve um diário tenta se colocar sob a proteção dos dias comuns) e, ao mesmo tempo, de se arriscar a perder a vida, pois o tempo dedicado a registrar experiências - ou até mesmo inventá-las - poderia ser empregado vivendo-as efetivamente.

Bolor é, portanto, um espaço em que a escrita se volta para a escrita, um espaço do $t u$ e do $t u d o$, um diário político que também é romance, uma forma de partilha do sensível onde arte e política se fundem. Em Bolor, a experiência estética realiza sua promessa suprimindo sua particularidade, pois constrói uma forma de vida comum indiferenciada, onde arte e política, trabalho e lazer, vida pública e existência privada se confundem; ao mesmo tempo, a experiência estética na obra define uma metapolítica, 
pois se compromete a "realizar realmente aquilo que a política realiza apenas aparentemente: transformar as formas da vida concreta” (RANCIÈRE, 2005b, p. 7). Dessa forma, se Bolor, enquanto romance, apresenta uma forma nova, por que não pensar que ele também sugere uma nova forma de olhar o mundo, uma nova forma de se fazer política?

\section{REFERÊNCIAS BIBLIOGRÁFICAS}

ABELAIRA, Augusto. Bolor. 4. ed. Lisboa: Bertrand, 1978.

BLANCHOT, Maurice. O livro por vir. São Paulo: Martins Fontes, 2005.

DIDIER, Béatrice. Le journal intime. 2. ed. Paris: PUF, 1991 apud MACIEL, Sheila Dias. "Diários: Escrita e Leitura do Mundo" in Analecta, v. 3, n. 1, p. 57-62, 2002. Disponível em $<$ http://www.cptl.ufms.br/pgletras/docentes/sheila/diarios_escrita\%20e \%20leitura\%20do\%20mundo.pdf $>$. Acesso em: 7 abr. 2007.

LAFER, Celso. "Público/Privado - suas configurações contemporâneas para a temática dos arquivos" in Documentos Privados de Titulares de Cargos Públicos: um Debate de Jurisdição Arquivística. 2004. São Paulo: Instituto Fernando Henrique Cardoso, 2004. Disponível em < http://www.desaparecidospoliticos.org.br/noticias/nt_desarquivando6. html>. Acesso em: 30 abr. 2007.

RANCIÈRE, Jacques. A partilha do sensivel: estética e política. Tradução: Mônica Costa Netto. São Paulo: Editora 34, 2005a.

. "Política da Arte" in Encontro Internacional Situação \# 3 Estética e Politica. 2005, São Paulo. Anais eletrônicos. São Paulo: São Paulo S.A. práticas estéticas, sociais e políticas em debate, 2005b. Disponível em $<$ http://www.sescsp.org.br/sesc/images/ upload/conferencias/206.rtf>. Acesso em: 15 mar. 2007. 